\title{
Brazil's Finest National Park
}

\author{
Francisco Erize
}

Maned wolf, giant armadillo, giant otter, giant anteater, and marsh and pampas deer are among the endangered species to be found in the Parque Nacional das Emas, the National Park of the Rheas, in Brazil. But the park is in danger of losing much of its value because boundaries were wrongly drawn and vital areas omitted. The author urges the need for international funds to help Brazil create in Das Emas a well planned, well guarded and well equipped park that will be outstanding in Latin America.

The central plateau of Brazil - the Planalto Central - is a high, gently undulating plain varying in altitude between 650 and 1000 metres, with an intricate system of streams and rivers that collect the abundant rainfall of the wet season. Where the red soil tends to clay there is grassland, and where sand there is woodland, which consists of low, twisted, usually well spaced trees; the river banks are lined with gallery forest, and alleys of the buriti palm Mauritia vinifera border the lesser streams. In the marshes of the flat low areas the riverine forest forms circular island patches. Today most of this tropical savanna has been developed into ranches for cattle breeding. The human population is increasing rapidly as a result of Brazil's industrial development and the establishment on the plateau of the country's new capital, Brasilia. Inevitably the wildlife is disappearing, and there can be little doubt that in the very near future there will be no room for wild creatures in the Planalto.

There are four national parks on the Planalto: Brasilia, an attractive, small park with several interesting endemic plants but few animals; Chapada dos Veadeiros, which includes several ranches and is reported to have serious problems with human interference; Aranguaia, which is more in a transition area between the Planalto and the Amazon basin, and Das Emas. And the last is the only real haven for the wildlife that was once widespread in central Brazil. Despite its comparatively small size (100,000 ha.) it offers a good sample of the Planalto habitats, including a number of small watercourses, the sources of two important rivers, riverine gallery forest and marshes, large areas of grassland (the campos), and some open woodland (the cenados) consisting of small thinly distributed trees seldom more than nine feet high: Large numbers of rheas and pampas deer, although scattered in small groups, roam both campos and cenados. Tapirs, white-lipped peccaries and pacas are said to be common in the riverine forest from which they come out to graze. The abundance of termites - some fields are just one big termite hatchery with one mound every twelve feet in all directions - supports a large population of giant anteaters. Even the maned wolf and the giant armadillo, both rare and endangered species, may be found here.

Das Emas is unique among South American national parks in that the wildlife, including large mammals, can be easily observed, whereas in most parks it is secretive, elusive, and well-hidden in thick vegetation. During the week I stayed in the park, there was not a single day in which I did not see 


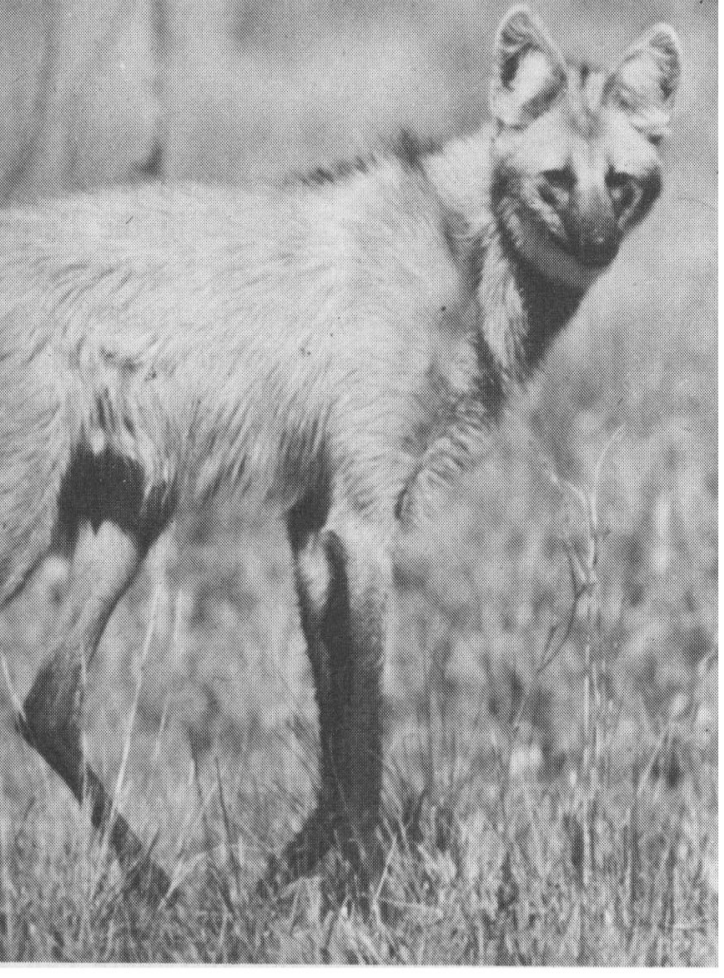

\section{WILDLIFE \\ IN \\ PARQUE DAS EMAS \\ Francisco Erize}

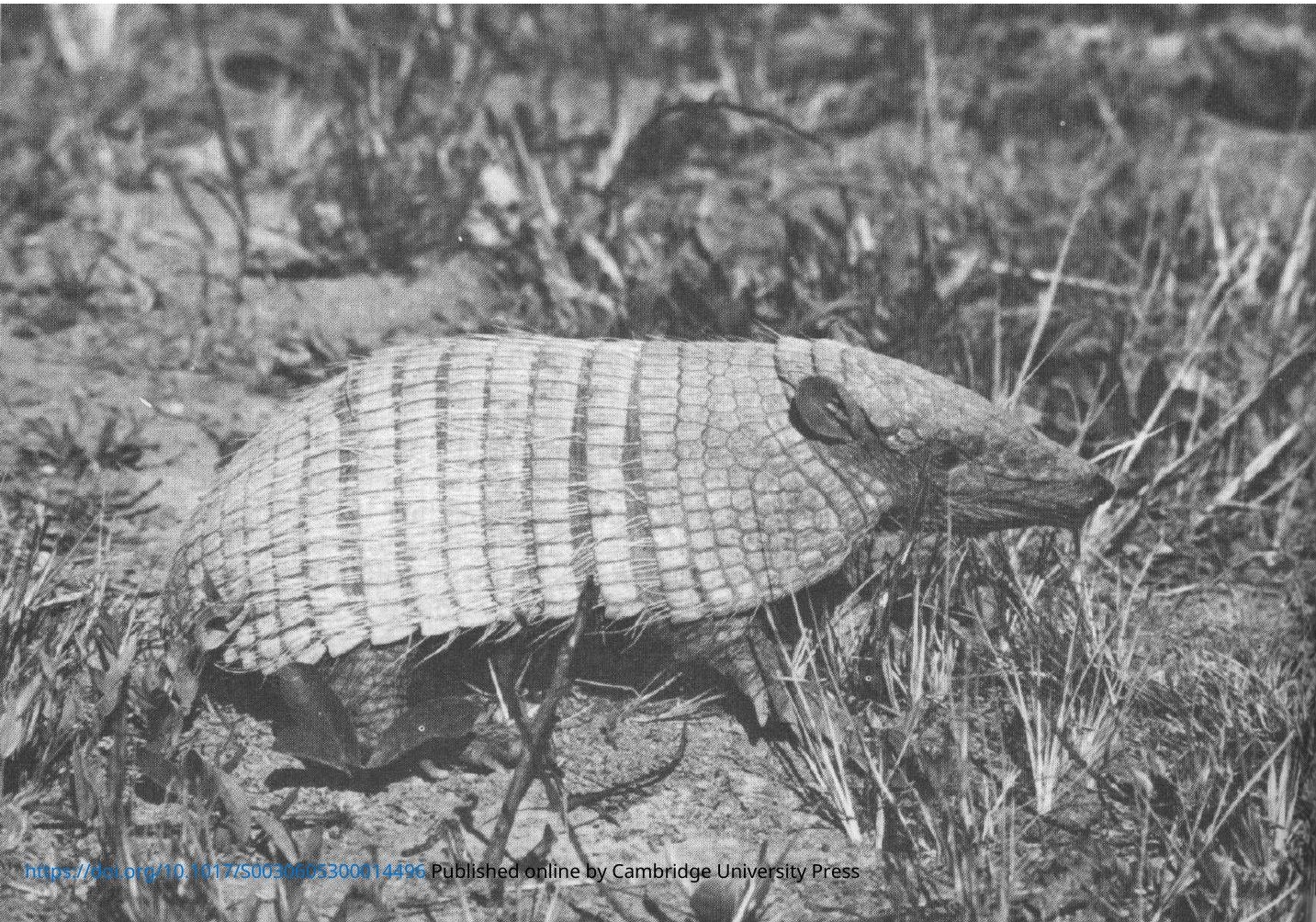




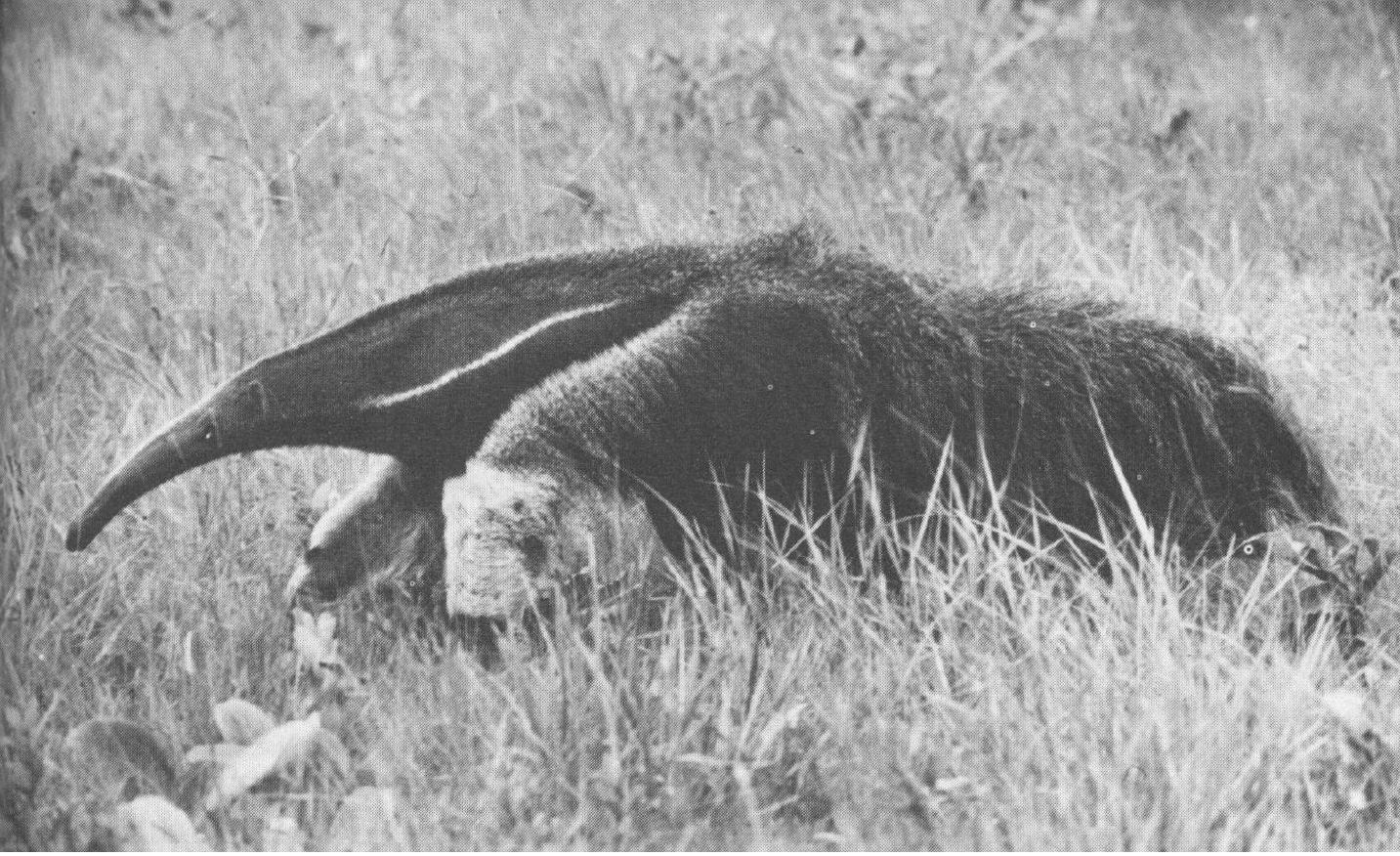

Opposite Maned wolf Chrysocyon brachyurus

Below Six-banded armadillo Euphractus sexcinctus

Above Giant anteater Myrmecophaga tridactyla. Below. King vulture Sarcoramphus papa

Pampas deer Blastocerus bezoarticus
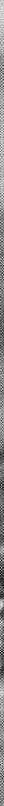


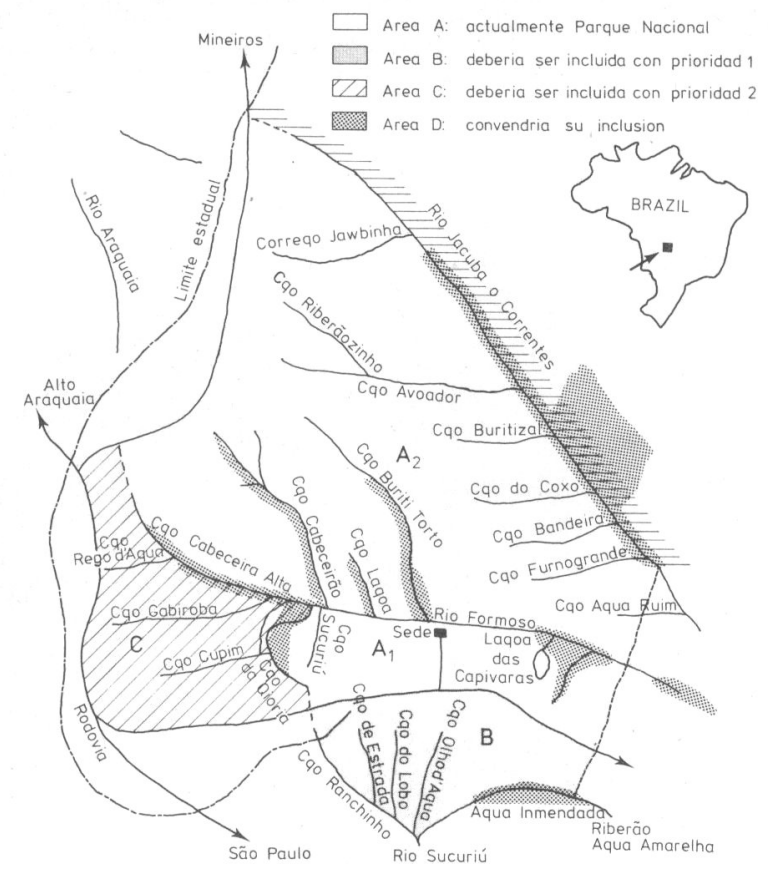

DAS EMAS NATIONAL PARK

at least 30 deer, 20 rheas, three giant anteaters, a fox and armadillos, - hairy, six-banded or naked-tailed. I never saw the giant armadillo, whose nocturnal habits and reduced numbers make it extremely difficult to see, but frequent diggings were convincing evidence of its presence. With the maned wolf I was more fortunate, and had one excellent view. According to local information it is not rare in the park, although so large a predator may never be very numerous, but it is the type of animal that is difficult to meet, and therefore my sighting and two others by the only other recent visitors, who only stayed a couple of days, seem encouraging signs of a healthy population.

But while Das Emas may become a South American Serengeti, that is, about the best park on the continent in terms of wildlife abundance and ease of watching it, a lot needs to be done now to make it a real park and not just an interesting possibility. The staff consists of the administrator, who can only be there part-time as the administrative office is some 300 miles away, and a single ranger, who has to police an area of about 250,000 acres. The most that the two men can hope to achieve is, through careful public relations, to get the neighbouring ranchers to accept the park and respect its regulations, and not regard it as a no-man's land. For efficient control the headquarters should be inside the park, with some six ranger stations and at least a dozen rangers equipped with vehicles and radio transmitters. Much of the park's perimeter will have to be fenced to keep out cattle from the neighbouring farms - it came as quite a shock to meet a steer in the most inaccessible part of the park; a fence would also help to keep out motorised poachers. The practice of allowing cattle into the park not only means competition for the wild grazing animals and the danger of overgrazing, but also frequent unchecked intrusions by stockmen who are potential poachers, and there is one farm inside the park which will have to be removed. As it is, a 


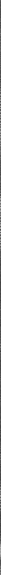

\section{CRESTED SERIEMA Cariama cristata}

hunting party can easily drive off the roads and into the park without the slightest chance of the ranger finding out in time.

It was the greatest misfortune that when the park was created the original plan was not followed. As created on January 11, 1961, by decree No. 40.874 , the park was intended to include areas covering the sources of the Jacuba, Formoso and Sucuriu rivers, but a later decree (No.70.375 of April 6, 1972), which established more precise boundaries, left out part of the sources of the Formosa and all those of the Sucuriu, with the result that the Formosa, the park's central water system, is not completely protected. Some streams flow through ranches and there is no way of protecting their purity. Moreover, the riverine forest that borders even the smallest streams is a different habitat, and shelters a different fauna from the grasslands and woodland that form the bulk of the park. As much as possible of this should be inside the park, whereas, with the present boundaries, much of it is wasted, part lying outside the park and a lot more on the park's demarcation line, where wildlife protection cannot be efficient.

Another difficulty is that these present boundaries may create an ecologically incomplete unit in the south of the park. At present the area marked B on the map is very little exploited. The settler there has few cattle and has been persuaded by the park's administrator and the ranger not to hunt. Thus the whole area to the south of the Formosa extending to the Sucuriu (maps A1 and B together) is effectively part of the park, with pampas deer, rheas, anteaters, screamers etc., roaming all over it. But once it is developed for intensive farming this wildlife may be confined to a narrow strip (area A1). No in-depth ecological study of these species has been made to discover how much they would be affected, but it seems unlikely that they would cross the Formosa river often enough to use all the ground they may require. If the range indeed proved too small, and the river a barrier for their ordinary purposes, this area, which today teems with wildlife, would lose all its value.

Planning for Das Emas must be on a big scale, for this could certainly be one of the world's most remarkable national parks. Today there are few 


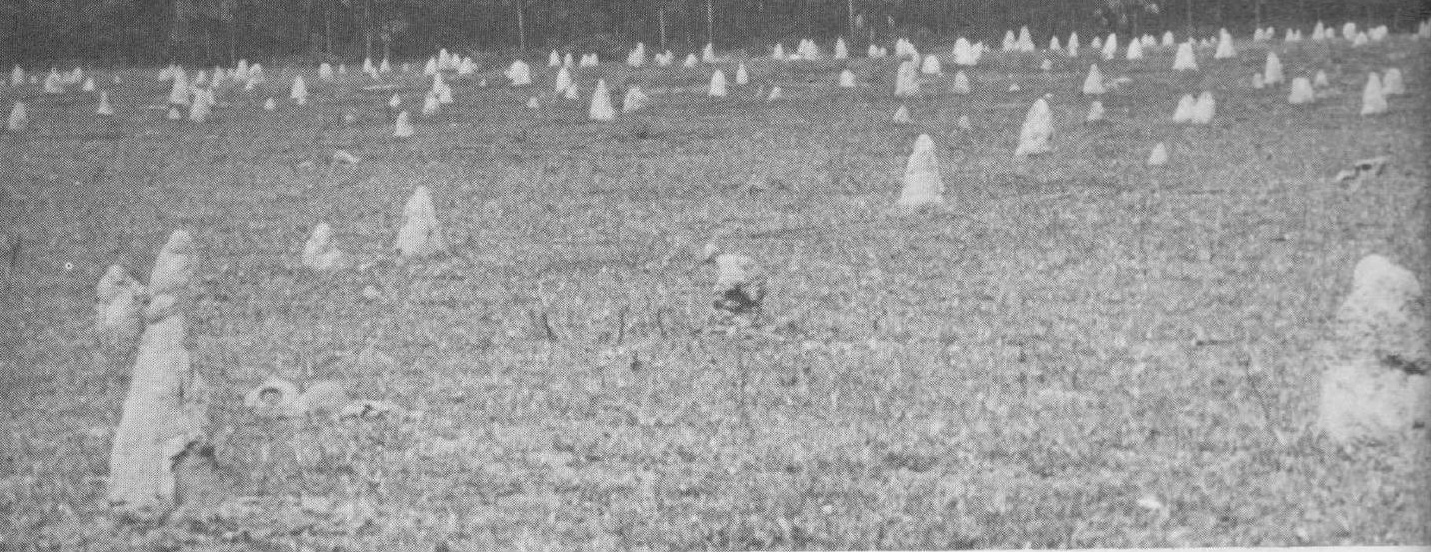

TERMITE HILLS in Parque das Emas, with riverine gallery forest behind

visitors, for the park is only accessible by a dirt road, there is no lodging near it, no roads inside it, and four-wheel-drive vehicles are essential to go very far. But, once properly organised, the flow of tourism this park will generate will fully compensate the Brazilian government for any funds and effort invested now. The park organisation is not wealthy, nor does it have the size and power that a country with Brazil's natural heritage requires. The parks are mostly located in the eastern and most populated part of the country, and they preserve mainly comparatively small areas featuring some important geographic or scenic site, or some special plant community. They do not include any large tract of Amazonia and the Pantanal.

The Xingu National Park in Amazonia is more a reserve for the wild Indian tribes, and when development comes for them, which may seriously conflict with wildlife, conservation of the latter will have a very low priority. In the Pantanal the Caracara Reserve, which existed on paper only, has been deproclaimed, ${ }^{*}$ and the creation of a proper national park there is urgent. The only other park where a good example of one of the country's important areas is preserved is the Iguaçu National Park, with 180,000 ha., but the development that will follow the dam-building is a serious threat.

Brazil is an expanding country, where people still have much of a pioneer mentality and wildlife conservation is not at all a widespread concern. But if international. conservation organisations were to support and contribute funds to the development of Das Emas into a model park - and Brazilians do not have the extreme susceptibility about foreign influence that much of South America displays - they might trigger larger government support as the authorities came to realise that, if international bodies are prepared to help, the matter is important. Otherwise the park service may often be confronted with a general indifference at higher levels of government.

Francisco Erize, San Martin 50, Cap. Fed., Argentina.

*As we go to press we learn that this decision has been reversed and the Caracara reserve is to be enlarged to make it a viable ecological unit-Editor. 